\title{
Towards an Understanding of the Complexity of Creative Efforts: A Conflict and Negotiation Perspective
}

\begin{abstract}
Saleem Gul ${ }^{1}$, Muhammad Nouman ${ }^{2}$, Aamer Taj ${ }^{3}$, Shahid $\mathrm{Ali}^{4}$
Abstract

This paper examines movie projects from the perspective of organizational complexity. Drawing on qualitative data collected from production efforts within Pakistan's movie industry, this paper argues that there are causal relationships between the themes of quality, money, rework, malpractice, delays, and cancellations. Furthermore, feedback loops are present between the themes of 'quality, money, and rework' and 'quality, money, and malpractices'. These loops are consequential in that they often lead to contract cancellation, although the cause of cancellation is different in each case. Whilst the importance of these loops cannot be overstated, we argue that these concepts emphasize the non-linear, emergent, and stable/unstable nature of creative efforts.
\end{abstract}

Keywords: Complexity, management, conflict, negotiation.

\section{Introduction}

Conflict and negotiation pervade businesses of all types. Surprisingly, conflict within creative efforts such as movies and television productions is a concern that has received little attention from the research community both internationally and locally. Additionally, the role played by these conflicts in adding to the complexity of the process is something that has not been examined at all. Therefore, this study is concerned with understanding the process through which conflict and negotiation are enacted and explain how they contribute to the 'complexification' of the process. This is achieved through a focus on unraveling patterns of occurrence of conflict and negotiation and exploring these further to identify the loopbacks through which complexity arises. The findings presented in this study are based on the analysis of qualitative data collected from three creative efforts from within the Pakistani movie industry. The focus of this study will be on task and afflictive conflicts, whereas relational conflicts will not be studied as these are beyond the scope of the study.

We begin with a brief review of the relevant existing scholarship on conflict and negotiation and complexity theory. Despite the significance of this frequently critical literature, we point to its limited engagement with small and medium enterprises

1 Dr. Saleem Gul is the corresponding author, email: s.gul@imsciences.edu.pk

2,3,4 Assistant Professor at the Institute of Management Sciences, Peshawar. 
in general and creative production efforts in particular. Then our discussion focuses on the data gathered as a part of this study. Here we explore how our respondents experienced conflict. Lastly, we elaborate on the way feedback loops arose within the situations experienced by our respondents and how these loops go on to contribute to the complexity of the process. Finally, the article concludes by arguing that the existence of the underlying feedback loops within the data point to the essentials of complexity, i.e. non-linearity, emergence, and stability and instability.

\section{Literature Review: Conflict and Complexity}

This section presents the literature review on conflict and complexity. It is broken into two key parts, where section A presents a brief but to the point review of conflict in general and section $\mathrm{B}$ presents a review of literature of complexity.

\subsection{Conflict}

Conflict has been defined in many different ways. However, most of these definition hold a negative view of conflict, e.g. see (Coser, 1956; March \& Simon, 1958; Deutsch, 1973; Deutsch \& Coleman, 2000; and Reichers, 1986). Conversely, some focus on the positive aspects of conflict. For example, Socklingam and Doswell (1999) identify its problem solving benefits, while Coser (1956), Deutsch (1973) focus on its positive effect on organizational commitment.

The presence of conflict is associated with a firm commitment and intention of an employee to stay (Cox, 1998; Cox, Jones, \& Collinson, 2006), i.e. reduced turnover in the organization. Initially, conflict was classified into two categories, the functional or dysfunctional (Pondy, 1967b). The 'functional' conflict implies that certain types of conflicts may actually be good. Later, work by other authors proposes a similar view of conflict via their two-model (normative and dynamic) approach to conflict. Conflict is perceived differently depending on the culture in which it takes place, e.g. in normative and dynamic cultures (Chua \& Gundykunst, 1987).

Jehn $(1994,1995)$ classifies conflicts into two types: (1) 'task conflict', which refers to cognitive disagreements arising from differences in perspective, ideas and opinions (Jehn \& Mannix, 2001; Chen, 2006) and (2) 'relational conflict', which refers to 'affective disagreement' stemming from personal preferences and disaffection - it includes annoyance and animosity among individuals (Amason \& Sapienza, 1997). Task conflict is positive because it relates to innovation and quality (West \& Anderson, 1996), increased constructive feedback (Jehn, Northcraft, \& Neale, 1999), affective decision-making (Amason, 1996), and reduced 'group-think' (Turner \& Pratkanis, 1994). Relational conflicts or value-goal conflicts (Leung, Liu, \& Ng, 
2005) are perceived negatively (due to their consequences), e.g. the negative effect on 'group climate' and team effectiveness (Jehn, 1997). Therefore, relational conflicts are discouraged (De Dreu \& Van de Vliert; 1997, Jehn \& Mannix; 2001, Simons \& Peterson, 2000). However, according to Medina, Munduate, Dorado, and Guerra (2005), these conclusions are based on studies that individually examine the effect of only one type of conflict on team performance (e.g. Amason, 1996; Jehn, 1994, 1995) while ignoring the tandem effect of both (Amason and Mooney, 1999).

Task and relationship conflicts are different in their nature but they are not mutually exclusive. Task conflicts refer to cognitive disagreements arising from differences in perspective, ideas and opinions, while relational conflicts refer to 'affective disagreement' arising from personality mismatches. According to Jehn (1997), task conflicts transform into relationship conflicts because task based criticism may be misconstrued as a personal insult (Amason, 1996), evoking evasive responses. However, this happens when there is an abundance of task conflict (Jehn, 1997). Alternatively, relationship conflicts affect task performance, but this relationship has not yet been conclusively proved (De Dreu \& Weingart, 2003; De Dreu, 2006).

Rahim (2001) argues that for a social system to benefit from conflict, it must labor to reduce the negative effects of conflict and nurture its positive effects. A conflict's positive or negative effects are determined by its characteristic, desired outcome, and choice of conflict management strategies (Jameson, 1999). Conflict intensity varies and depends on whether managers are able to harness its productivity or not (Coser, 1956; March \& Simon, 1958). An excess of conflict reduces organizational commitment (Bess \& Dee, 2007; Mintzberg \& McHugh, 1985) and is an impediment to trust, empowerment, and firm commitment (Janssen, 2004). Normative suppression of conflict is not desirable because it lowers trust and is dysfunctional to the organization as a whole.

High task conflict reduces team commitment and satisfaction (Amason and Sapienza, 1997), is stressful, generates opposition, leads to discontent, and creates reluctance towards future work (Jehn, 1995). A moderate amount of task conflict is ideal (Brown, 1983) because it fosters innovation and intra-group trust (De Dreu, 2006; Lovelace, Shapiro, \& Weingart, 2001). Alternatively, De Drue and Weingart (2003) accept both task and relationship conflicts as disruptive. While, De Drue (2008) posits that traditional thoughts about the benefits of workplace conflict are unfounded and methodologically flawed, he argues that the beneficial and positive benefits of conflict are rarely realized. Organizational conflict occurs either intra-organizationally or inter-organizationally. Intra-organizational conflict occurs at different levels and comprises conflicts that are: intra-personal, dyadic, intra-group, and intergroup (Rahim, 2001). 
Although conflict cannot be eradicated completely, it can certainty be managed or resolved. However, managing individuals' perceptions, preconceived ideas, and learned behavior is not simple ${ }^{5}$. Conflict resolution and management are considered as means to achieving the ideal levels of conflict within a business setting. More formally, conflict management prevents new conflicts from arising and conflict resolution reduces the intensity of conflicts that have escalated.

The working definition of conflict adopted by this study is that of Jordan (1990), as it is more holistic in nature who defines conflict as when a difference between two (or more) people necessitates change in at least one person in order for their engagement to continue and develop - the differences cannot coexist without some adjustment.

\subsection{Complexity}

Literature on complexity attempts to describe the complexity landscape and highlights developments of direct practical consequence to the field of management. Some examples identified by Cicmil, Cooke-Davies, Crawford, and Richardson (2009a) and Cooke-Davies, Cicmil, Crawford, and Richardson (2007) include sensitive dependence on initial conditions (i.e. butterfly effect), strange attractors, fractals, edge of chaos, universality, dissipative structures, self-organizing systems, emergence, complex adaptive systems, and indeterminacy ${ }^{6}$. These can be categorized as belonging to non-linearity, emergence, or stability / instability?

The effect of non-linearity is two pronged. Prigogine and Stengers (1984) argue that it 'may produce an order out of the chaos' while in different conditions it may 'be responsible for the destruction of the same order, eventually producing a new coherence beyond another bifurcation'. Stacey, Griffin, and Shaw (2000) posit that it brings recognition to the concept of feedback amplification and introduces the idea of 'non-linear responses into a chain of circular causality'. These may lead to unexpected and unintended results; thus eliminating the assumption that a system will settle to an equilibrium state. Therefore, the system is then no longer self-regulating,

5 According to Popper, such an effort is considered 'utopian engineering' (Popper, 1966). According to Burton (1998), because conflicts originate from social problems, therefore their resolution and management is possible. This is made possible by removing the source of conflict and thus adjusting institutional and social norms as needed.

6 Two concerns exist: (1) although both texts offer a concise treatment of each development, the reader is left to form associations from each to specific business problems or instances within business, which is attested to by Stacey, Griffin, and Shaw (2000) who argue that such parallels with complexity science serve as a source of analogies. (2) The review of literature for this study did not reveal any studies that contributed empirically to any of these concepts. Nevertheless, as expressed before, this does not discount the potentiality of their practical application.

7 Non-linearity includes: Sensitive dependence on initial conditions, self-organization, and complex adaptive systems. Emergence includes: Dissipative structure, emergence, and indeterminacy. Stability/Instability includes: Fractals, Edge of chaos, and universality. 
rather it is self-influencing (within which it may acquire the subtype: self-sustaining or self-destructive). A study of non-linear systems leads to the conclusion that long-term predictability is not possible (Lorenz, 1963), as it is impossible to precisely identify initial condition ${ }^{8}$ (Stacey et al., 2000).

Emergence and self-organization build on the concepts of non-linearity. Lewes (1875) argued that every resultant is either a sum (when their directions are the same) or a difference (when their directions are opposite) to the co-operant forces. Further, every resultant is easily decomposable into its components because these are homogeneous and commensurable. The resultant is emergent when, instead of adding quantifiable motion to measurable motion, or things of one kind to other, there is a co-operation of things of unlike kinds. The emergent is unlike its components to the extent that these are incommensurable, and it cannot be reduced to their sum or their difference. The cause of emergence within organizations and cultural evolution is attributable to human rationality or lack thereof (Marion, 1999), and the intertwined nature of cooperative power and conflict (Kauffman, 1993, 1995).

\section{Data Analysis}

Our data sources include two movies (docudrama and horror) and a television serial, where the former two are Lollywood efforts and the latter is based in Pollywood. Data were collected from two persons from each of the cases using causal-maps following Bryson, Ackermann, Eden, and Finn (2004) and Ackermann, Eden, and Cropper's (1992) method. Conversations between the researcher and respondents were also recorded using a data recorded and later transcribed. Memos were noted during the interviews based on which detailed interview notes were produced immediately following each set of interviews. Additionally, two production sequences were observed and observation data were recorded manually.

The compiled data was analyzed following Miles and Huberman's (1994) recommendations. A total of 8 themes in the context of which conflicts within the productions arose were found within the data. In order to ensure data traceability through and to prevent in-text repetitions, truncated names in the form of codes were assigned to each production effort, see Table 1 .

Interviewees from each production are identified using a coding plan, i.e. the production code precedes a unique number identifying each person interviewed (e.g. LD-1 refers to respondent 1 from the Lollyword Docudrama), see Table 2.

8 However, short-term predictions are possible due to the theory of determinism, which is a theory of causality that is unconcerned with the measure of initial conditions. The reader may also be interested in looking up works by Poincare and Laplace on this topic. 
Table 1: Codes assignment

\begin{tabular}{|l|c|}
\hline Production & Code \\
\hline Docudrama & LD \\
\hline Horror Movie & LH \\
\hline TV Serial & TV \\
\hline
\end{tabular}

Table 2: Interviewee codes and respondents positions

\begin{tabular}{|l|l|c|}
\hline Interviewee Code & Position Held & Interview Duration (in Minutes) \\
\hline LD-1 & Producer/Director & 60 \\
\hline LD-2 & Actor & 30 \\
\hline LH-1 & Producer/Director & 60 \\
\hline LH-2 & Camera-man/Director & 60 \\
\hline TV-1 & Producer/Director & 90 \\
\hline TV-2 & Assistant Director & 90 \\
\hline
\end{tabular}

\subsection{Identified Conflicts}

\subsubsection{Political Pressure}

One of the movie productions experienced limited political pressure. This incidence involved gaining approval from the Pakistan Censor Board (PCB). The PCB is a body that filters movie or television program for general screening within the Pakistan.

However, despite the existence of the PCB, the local cinema industry is notorious for the vulgarity in its productions. One interviewee recounted his experience with the PCB. Below is an example of the possible conflicts arising due to corruption.

[LH-1 \& LH-2] "They said my movie was too risqué. I tried to reason but they weren't relenting; one choice I had was to say 'to hell with it' and just release the movie on a CD, but I wanted to exhibit my work in the cinema's . . . they wasted a lot of my time ... it took several trips to their offices and applications to finally get them to listen. When they did, I showed them clips of Pashto movies to show them some of the junk they had okayed ... this got my case moving. There are clearly double standards within the industry ... i.e. for those that have influence or pay up for the rest of us."

The docudrama had no conflict with the PCB as the producer released the drama on DVD (a medium of production that is not under the control of the PCB). We conclude that use of political pressure/meddling leads to delays or work stoppages. 


\subsubsection{Time}

On the horror movie, time delays drove conflicts. An example was presented in section ' $b$ '. While another example, presented under item ' $g$ ' exhibits that poor quality work translates into delays and thereby gives birth to conflicts. On another production the tardiness of the movie cast was a concern because it consumed available time contingencies:

[LH-2] "Our actors and actresses think they are Hollywood stars and are never on time for the shooting. They don't mind keeping 20 people waiting around for them ... we have a tight schedule, have rented equipment . . . such delays eat into our schedule and if an actual problem arises then we don't have any time left to deal with it. I've had plenty of late-nights ...."

Alternatively, schedules set by the HQ resulted in time related conflicts on another production.

[TV-1 and TV-2] ". . . by the time the HQ gave us the screen plays for the next 4 episodes there was one week remaining for schools to go on summer break. We all of a sudden had 4 episodes to shoot in a week, this included negotiating with the schools to give us access. We talked to the bosses but they didn't listen. We couldn't ask the schools to be kept open until late so we had to breakup into two teams. Unfortunately, one of our cameras had a bad microphone so this meant that we had to dub the dialogue in the studio."

We conclude that time delays lead to consumption of contingencies and extra resources. Also, excessive delays result in shrinking of the time available to completion, which leads to poor quality of workmanship and rework.

\subsubsection{Availability of Resources}

Availability of resources is another concern within creative efforts due to the general negative perception. As one respondent explained:

[LH-1 and LH-2] ". . . these hardworking people can't tell anyone they work in the theater industry."

This relates to the perception of another respondent, who said that people believe that:

[LD-2] ". . . anyone working in the arts is a prostitute. ..."

This was a source of unique problems on one production, where a sexually explicit 
private cell-phone video of one of the lead actresses, who moonlighted as prostitute, ended up in the mass market during the filming of the movie production.

[LD-1] "She had to go into hiding as the Taliban were now after her. We didn't want her around the movie site any more either. . . what if they would come after her here. Luckily we had finished filming her scenes. . female actresses are difficult to find here because of the culture and perverse image that industry has created for itself."

Uneducated or under-educated actors were also a problem on another production. One respondent elaborated on a situation where one of his cast members consistently mispronounced or spoke using colloquial language because she had received no formal schooling:

[TV-1 and TV-2] "... results in a lot of rework for me as she has to be coached all the time. . I I also have to be on guard to make sure she didn't say something wrong. Sometimes, we don't catch a blunder but later on during editing we find it, we have to then get her to come and act the scene again or do a voice over."

Talibanization was another factor that contributed to limiting the availability of resources. See examples provided in sub-section 'j' on law and order. We conclude that lack of resource availability leads to poor quality and rework.

\subsubsection{Policies}

On one production, conflict was due to misappropriated or unclear policies and practices. For example, see incidence about the horror movie and the CBP, narrated in sub-section 'b'. Alternatively, the docudrama was not encumbered by the policies of the government by opting to release their movie into the market directly on a DVD.

On another production the decisions were followed blindly as they came from the CEO. For example:

[TV-1 and TV-2] "The CEO tells us what to do, we have to follow whether we like it or not."

We conclude that poor policies lead to extra costs, poor quality, delays and rework.

\subsubsection{Money and Quality}

Financial concerns pervaded all productions. Mostly these related to concerns regarding the budget and controlling expenses. This is possibly because the LD and TV productions operated under a fixed budget, which meant that spending on the production was limited to the essentials and purchase choices were restrained. There- 
fore, producers were very careful during procurement and preferred in-house work where possible. For example, the producer of the LD himself did the editing work, while on the TV production it was completed using the channel's permanent staff. On the LH production the producer/director being a novice felt obligated to hire professional editors and cameraman [sic], who at times also provided directorial support.

Respondents on all productions opinioned that their productions suffered from poor quality because of limited budgets. This was explained thus:

[TV-1 and TV-2] "I have two choices, to cast an actress who is educated and is able to deliver the dialog quickly and without mistakes or to hire one who is uneducated and makes multiple mistakes each time. I would prefer the first as she's a professional but I have to go with the second choice because she's cheaper to employ."

Another respondent narrated an experience where a costume maker had to be changed:

[LH-1 and LH-2] ". . . he was providing such cheap quality costumes that some would rip during the shooting and we wouldn't be able to reuse them. I was paying him three times more money than what other tailors were asking because I needed them quick. . . ended up going to him twice or three times a day because he wasn't providing them at the times committed to. . . eventually I tried another tailor at random and found that he did the work better, faster, and cheaper. . . rather than getting into a contract with anyone, I would just go to different people and get them to do the work."

We conclude that money and quality issues lead to rework and contract cancellation leading to delays.

\subsubsection{Cheating and Bribery}

Explicit cases of bribery were not reported by any production effort. However, in the interview excerpt discussed in the context of political pressure (subsection 'b'), a possibility for bribery existed in the interactions with government departments. An incidence of cheating in which a contracted party was providing sub-quality workmanship has already been discussed in sub-section ' $\mathrm{g}$ '.

\subsubsection{Law and Order}

Issues stemming from law and order situations wreaked havoc on the local movie industry. An example of how this happens has been discussed in section 'e'. All the respondents agreed and provided similar feedback, most explicated incidents involving 
famous actors, actresses, and musicians who have been killed, fled the country, are in hiding, or 'repented' their past and abandoned the profession.

[LD-2] "many of my friends and colleagues have been targeted just because they were actors. I fear for my life all the time. . . we have talked to the govt. over and over again but they are doing nothing to protect the industry or us. Consequently limiting further the already limited human resources."

We conclude that law and order issues lead to lack of resource availability.

\subsection{Negotiation Tactics Used}

When conflict arises from the interactions with the functional organization (based on data gathered from the TV serial production), the production staff chooses to avoid and does not offer any resistance. This is because the production staff feels that they do not have a platform from where to voice their opinions or grievances.

When conflict between contractors and production staff relates to poor quality workmanship or material, the production staff chooses a confrontation strategy. If agreement is not reached then the contract is terminated.

\subsection{Feedback Loops}

Table 3: Negotiation tactics used: When and why

\begin{tabular}{|l|l|l|}
\hline Interview Case & Negotiation Tactics Used & Used When \\
\hline Disagreement with PCB & Face-to-face meeting & $\begin{array}{l}\text { PCD would not approve clearance } \\
\text { certificate }\end{array}$ \\
\hline Disagreement with cast & Confrontation & Work is delayed \\
\hline Demands from main office & Avoidance & Work will be delayed \\
\hline Poor quality work (cast) & Compromise & Budgetary constraints \\
\hline Poor quality work (designer) & Confrontation & Visibly poor quality \\
\hline
\end{tabular}

Next we analyzed the dataset for the occurrence of loops using Decision Explorer Software, a commercially available Computer Aided Qualitative Data Analysis Software (CAQDAS). A distinct relationship within the dataset between the concepts of quality and money and quality and rework was found. Four of the identified six loops within the data showed a direct relationship between quality and money, while four showed a relationship between quality and rework (out of these, two were found leading to money conflicts).

The explanation of the relationship between conflicts over quality and money 
is founded on the captured interviews. We find that the relationship is three staged: (1) conflicts between the production team and contractors because of poor quality of work lead to payment stoppages by the production manager for the work performed until the problem is resolved, (2) conflicts over quality lead to further conflicts about money, where the contractors objects to the rework, arguing that they do not want to pay the added expenses, and (3) attempts by contractors to recover the expenses incurred as a result of rework including reduced quality of work, or by demands for additional funds via the issuance of escalation claims. In the case of 1 above, stopped payments were significant in that the contractors responded by seizing the production work. Therefore, quality conflicts not only led to money issues but also gave rise to delays and malpractices. Further, conditions where work was purposefully delayed, false escalation claims issued, contract were violated, poor quality etc., resulted in formal negotiation in the form of a 'jirga' (i.e. gatherings of elders). Other loops in the dataset indicate that rework played an intermediary role in the relationship between quality and money conflicts. How rework related conflicts led to money conflicts has already been discussed above.

Next generalized loops were extracted using Decision Explorer. These explain how one type of conflict leads to another and the effects of feedback, see figure 1 . The term 'malpractices' is used to typify cheating, bribery, or theft. The term 'cancellations' means contract cancellation. N.B.: delays, quality, and money conflicts are the key conflicts within figure 1 based on their initiating or mediating roles.

The loops presented in figure 1 are not similar. As explained by certain researchers, some loops are 'vicious', i.e. produce unwanted and bad consequences, while other are 'virtuous'. The loops nature may be determined by looking at appropriate vignettes related to each theme. Elements of virtuosity and viciousness are present in case of quality and money, quality and rework, quality and delays, and money and delays; while viciousness is present in the loops of money and malpractice, delays and cancellations, and quality and malpractice.

We may further simplify figure 1 using decomposition. This results in deciphering those components of the figure which are actually feedback loops and those which are simply causal chains. After decomposing the full network diagram using Decision Explorer, two feedback loops emerged: (1) between quality, money, and rework and (2) between money, malpractice, and quality. Both of which are consequential to production studied in a way that they contribute to the creation of a vicious cycle of events during the production. The result of these loops is that they lead to the waste of time, effort, and finances. Additionally, if the production team is oblivious that it is trapped in a positive feedback loop, the consequences of their actions will be intensified and re-presented to them in the form of feedback. In conclusion, the 
conflict and negotiations transpiring across the two positive feedback loops discussed so far contributes to the complexity of the productions included in this study.

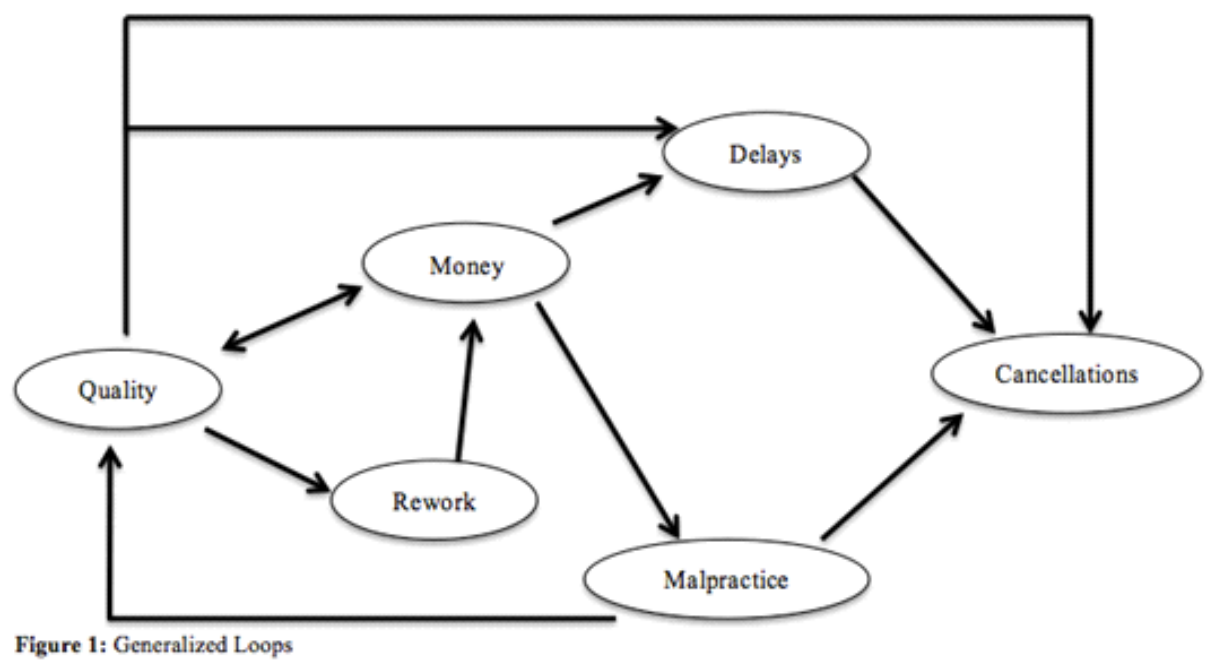

\section{Conclusion}

The underlying foundations of complexity are based on the concepts of non-linearity, emergence, and stability/instability. In the feedback loops identified in figure 1 , we get a clear sense that non-linearity and emergence exists, such that one type of conflict leads to another. Additionally, the reverse feedback to the initial type of conflict leads to further, possibly newer, conflicts.

These loopback are dynamic and indeterminate, i.e. although we can identify them, we cannot use them to make any long-term predictions. This in no means implies that absolutely no predictions are possible, rather the benefit we derive through the identification of these loops is that we can predict short-term behavior. This also implies that efforts geared to long-term predictability of events will not be of any benefit.

The concept of stability/instability is an inherent component of the feedbacks where there are episodes of instability followed by episodes of stability or vice versa. Systemic stability is achieved in the absence of feedback and instability occurs in the presence of (bad) feedback. Thus, creative production efforts, no matter how simple, may exhibit really complex behaviors and seemingly arbitrary processes may add to complexifying the efforts even more. 


\section{References}

Ackermann, F., Eden, C., \& Cropper, S. (1992). Getting started with cognitive mapping. Paper presented at the 7th Young OR Conference, University of Warwick

Amason, A. C. (1996). Distinguishing the effects of functional and dysfunctional conflict on strategic decision making: Resolving a paradox for top management groups. Academy of Management Journal, 39(1), 123-148.

Amason, A. C., \& Mooney, A. C. (1999). The effects of past performance on top management team conflict in strategic decison making. International Journal of Conflict Management, 10(4), 340-359.

Amason, A. C., \& Sapienza, H. J. (1997). The effects of top management team size and interaction norms on cognitive and affective conflict. Journal of Management, 23(4), 495-516.

Beals, A. R., \& Siegel, B. J. (1966). Divisiveness and social conflict: An athropological approach. Stanford, CA: Stanford University Press.

Bess, J. L., \& Dee, J. R. (2007). Understanding college and university organization: Theories for effective policy and practice. Sterling, VA: Stylus.

Bisno, H. (1988). Managing Conflict. Newbury Park, CA: Sage.

Boulding, E. (1962). Conflict and Defense. New York: Harper and Row.

Brown, H. I. (1983). A Philosopher Relpies. PsycCRITIQUES, 28(245-246).

Bryson, J. M., Ackermann, F., Eden, C., \& Finn, C. B. (2004). Visible thinking: Unlocking causal mapping for practical business results. London: John Wiley \& Sons.

Burton, J. W. (1998). Conflict resolution: The human dimension. The International Journal of Peace Studies, 3(1), 4.

Chen, M. (2006). Understanding the benefits and detriments of conflict on team creativity process. Creativity and innovation management, 15(1), 105-116.

Chua, E. G., \& Gundykunst, W. B. (1987). Conflict resolution styles in low and high-context cultures. Communication Research Reports, 4(1), 32-37.

Cicmil, S. (2003). Knowledge, interaction and project work: The perspective of complex responsive processes of relating. Paper presented at the 19th EGOS Colloquium, 'Project organizations, Embeddedness and Repositories of Knowledge', Copenhagen, Denmark.

Cicmil, S. (2006). Understanding project management practice through interpretative and critical research perspectives. Project Management Journal, 37(2), 27-37.

Cicmil, S., Cooke-Davies, T., Crawford, L., \& Richardson, K. (2009). Exploring the complexity of projects: Implications of complexity theory for project management practice. Newtown Square, PA: Project Management Institute. 
Cicmil, S., \& Hodgson, D. (2006). Making projects critical an introduction. In D. Hodgson \& S. Cicmil (Eds.), Making projects critical (pp. 1-28). New York, NY: Palgrave Macmillan.

Cicmil, S., \& Hodgson, D. (2006). New possibilities for project management theory: A critical engagement. Project Management Journal, 37(3), 111.

Cicmil, S., Hodgson, D., Lindgren, M., \& Packendorff, J. (2009). Project management behind the facade. Ephemera theory $\mathcal{E}$ politics in organization, 9(2), 78-92.

Cicmil, S., \& Marshall, D. (2005). Insights into collaboration at the project level: Complexity, social interaction and procurement mechanisms. Building Research and Information, 33(6), 523-535.

Cicmil, S., Williams, T., Thomas, J., \& Hodgson, D. (2006). Rethinking project management: Researching the actuality of projects. International Journal of Project Management, 24(8), 675-686.

Cooke-Davies, T., Cicmil, S., Crawford, L., \& Richardson, K. (2007). We're not in Kansas anymore, Toto: Mapping the strange landscape of complexity theory, and its relationship to project management. Project Management Journal, 38(2), 12.

Coser, L. A. (1956). The functions of social conflict. New York: Macmillan.

Coser, L. A. (1967). Continuities in the study of social conflict. New York: Free Press.

Cox, K. B. (1998). Antecedents and effects of intragroup conflict in the nursing unit. The Sciences and Engineering. Dissertation Abstracts International: Scienes and Engineering.

Cox, K. B., Jones, B., \& Collinson, D. (2006). Trust relations in high-reliability organizations. Risk Analysis, 26(5), 1123-1138.

De Dreu, C. K. W. (2006). When too much and too llittle hurts: Evidence for a curvilinear relationship between task conflict and innovation in teams. Journal of Management, 32(1), 83-107.

De Dreu, C. K. W. (2008). The virtue and vice of workplace conflict: Food for (pessimistic) thought. Journal of Organizational Behavior, 29(1), 5-18.

De Dreu, C. K. W., \& Van de Vliert, E. (Eds.). (1997). Using conflict in organizations. London: Sage.

De Dreu, C. K. W., \& Weingart, L. R. (2003). Task versus relationship conflict, team member satisfaction, and team effectiveness: A meta-analysis. Journal of Applied Psychology, 88(4), 741-749.

Deutsch, M. (1973). Conflicts: Productive and destructuve. In F. E. Jandt (Eds.), Conflict Resolution Through Communication (pp. 156). New York: Harper \& Row.

Deutsch, M., \& Coleman, P. (Eds.). (2000). The handbook of conflict resolution: Theory and practice. San Francisco: Jossey Bass.

Donohue, W., \& Colt, R. (1992). Managing interpersonal conflict. Newbury Park, CA: Sage.

Fenn, P. (2006). Conflict management and dispute resolution. In D. Lowe \& R. Leiringer (Eds.), Com- 
mercial Management of Projects: Defining the Discipline (pp. 234-269): Blackwell publishing.

Fink, C. F. (1968). Some conceptual difficulties in the theory of social conflict. Journal of Conflict Resolution, 12(4), 412-460.

Follett, M. P. (1925). Constructive conflict. In H. C. Metcalf (Eds.), Scientific Foundations of Business Administration. Baltimore, MD: Williams and Wilkins.

Gell-Mann, M. (1994). The quark and the jaguar. New York: Freeman \& Co.

George, J. M., \& Jones, G. R. (2005). Organizational behavior (3rd ed.). New York: Prentice Hall.

Henkin, A. B., \& Holliman, S. L. (2009). Urban teacher commitment: Exploring associations with organizational conflict, support for innovation, and participation. Urban Education, 44(2), 160-180.

Hocker, J. L., \& Wilmot, W. W. (1995). Interpersonal conflict (4th ed.). Dubuque, IA: Brown \& Benchmark.

Jameson, J. K. (1999). Towards a comprehensive model for the assessment and management of intra-organizational conflict: Developing the framework. International Journal of Conflict Management, 10(3), 268-294.

Janssen, O. (2004). The barrier effect of conflict with superiors in the relationship between employee empowerment and organizational commitment. Work and Stress, 18(1), 56-65.

Jehn, K. A. (1994). Enhancing effectivenes: An investigation of advantages and disadvantages of value-based intragroup conflict. International Journal of Conflict Management, 5(3), 223-238.

Jehn, K. A. (1995). A multi-method examination of the benefits and detriments of intragroup conflict. Administrative Science Quarterly, 40(2), 256-282.

Jehn, K. A. (1997). A qualitative analysis of conflict types and dimensions in organizational groups. Administrative Science Quarterly, 42(5), 530-557.

Jehn, K. A., \& Mannix, E. A. (2001). The dynamic nature of conflict: A longitudinal study of intragroup conflict and group performance. Academy of Management Journal, 44(2), 238-251.

Jehn, K. A., Northcraft, G., \& Neale, M. A. (1999). Why difference makes a difference: A field study of diversity, conflict and performance in work group. Administrative Science Quarterly, 44(4), 741-763.

Jordan, J. V. (1990). Courage in connection: Conflict, compassion, and creativity. Stone Center for Developmental Services and Studies, Wellesley College.

Kauffman, S. A. (1993). Origins of order: Self organization and selection in evolution. Oxford: Oxford University Press.

Kauffman, S. A. (1995). At home in the universe. New York: Oxford University Press.

Leung, M., Liu, A. M. M., \& Ng, S. T. (2005). Is there a relationship between construction conflicts and participants' satisfaction? Engineering, Construction and Architectural Management, 12(2), 149 - 167. 
Lewes, G. H. (1875). Problems of life and mind (Vol. 1). Boston: Osgood and company.

Lorenz, E. N. (1963). Deterministic nonperiodic flow. Journal of Atmospheric Sciences, 20(2), 130-141.

Lovelace, K., Shapiro, D. L., \& Weingart, L. R. (2001). Maximizing crossfunctional new product teams' innovativeness and constraint ahderence: A conflict information exchanges perspective. Academy of Management Journal, 44(4), 779-783.

March, J., \& Simon, H. A. (1958). Organizations. New York, NY: Wiley.

Marek, J. (1966). Conflict, a battle of strategies. In J. Lawrence (Eds.), Organizational research and the social science (pp. 64). London: Tavistock.

Marion, R. (1999). The edge of organization: chaos and complexity theories of formal social systems. Thousand Oaks, Calif.: Sage Publications.

Medina, F. J., Munduate, L., Dorado, M., \& Guerra, J. M. (2005). Types of intragroup conflict and affective reactions. Journal of Managerial Psychology, 20(3/4), 219-230.

Mintzberg, H., \& McHugh, A. (1985). Strategy formation in an adhocracy. Administrative Science Quarterly, 30(2), 160-197.

Pondy, L. (1967). Reflections on organizational conflict. Journal of Organizational Behavior, 13(3), 257-261.

Popper, K. R. (1966). The open society and its enemies. Volume 1 : The Spell of Plato ( $5^{\text {th }}$ ed.). London: Routledge \& Kegan Paul.

Prigogine, I., \& Stengers, I. (1984). Order out of chaos: Man's new dialogue with nature. New York: Bantam Books.

Pryke, S., \& Smyth, H. (Eds.). (2006). The management of complex projects: A relationship approach (2 ${ }^{\text {nd }}$ ed.): Blackwell Publishing.

Rahim, M. A. (2001). Managing conflict in organizations (3 ${ }^{\text {rd }}$ ed.). Westport, Connecticut: Quorum Books.

Reichers, A. E. (1986). Conflict and organizational commitments. Journal of Applied Psychology, 71(3), 7.

Robbins, S. P. (1974). Managing organizational conflict: A nontraditional approach. Englewood Cliffs, NJ: Prentice-Hall.

Simon, H. A. (1962). The architecture of complexity. Proceedings of the American Philosophical Society, 106(6), 467-482.

Simons, T. L., \& Peterson, R. S. (2000). Task conflict and relationship conflict in top management teams: the pivotal role of intragroup trust. Journal of Applied Psychology, 85(1), 102-111.

Socklingam, S., \& Doswell, A. (1999). Conflict in BPR. Knowledge and Process Management, 6(3), 146-153.

Stacey, R. D. (2001). Complex responsive processes in organizations: Learning and knowledge creation. London: Routledge. 
Stacey, R. D., Griffin, D., \& Shaw, P. (2000). Complexity and management: Fad or radical challenge to systems thinking? London: Routledge.

Thomas, K. W. (1992). Conflict and negotiation processes in organizations. In M. D. Dunnette (Eds.), Handbook of Industrial and Organizational Psychology ( $2^{\text {nd }}$ ed., pp. 889-935). Palo Alto, CA: Consulting Psychologists Press.

Turner, M. E., \& Pratkanis, A. (1994). Social identity maintenance prescriptions for preventing groupthink: Reducing identity protection and enhancing intellectual conflict. International Journal of Conflict Management, 5(3), 254-270.

Van de Vliert, E., \& De Dreu, C. K. W. (1994). Optimizing performance by stimulating conflict. International Journal of Conflict Management, 5(3), 211-222.

Walton, R. E. (1966). A theory of conflict in lateral organizational relationships. In J. Lawrence (Eds.), Operational Research and the Social Sciences (pp. 411). London: Tavistock.

West, M. A., \& Anderson, N. R. (1996). Innovation in top management teams. Journal of Applied Psychology, 81(6), 680-693.

Williams, T. (2002). Modeling complex projects. West Sussex, UK: John Wiley \& Sons.

Zey-Ferrell, M. (1981). Criticisms of the dominant perspective on organization. Sociological Quarterly, 22(2), 181-205. 
